\title{
Sistem Pakar Penanganan Penyakit Tanaman Jahe Dengan Metode Case Based Reasoning
}

\author{
"Petti Indrayati Sijabat', Sulindawaty²
}

\author{
${ }^{1,2}$ STMIK Pelita Nusantara, Teknik Informatika, Indonesia \\ Petti.jabat@gmail.com ${ }^{1}$, sulindawaty@gmail.com ${ }^{2}$ \\ * Corresponding Author
}

\begin{abstract}
Abstrak
Penurunan jumlah produksi jahe disebabkan berbagai faktor, salah satu diantaranya adalah serangan hama penyakit tanaman. Berbagai jenis hama biasanya menyerang dan menimbulkan kerusakan pada akar, rimpang, pangkal batang, batang dan daun. Untuk menangani penyakit pada tanaman jahe dilakukan penerapan sebuah sistem pakar yaitu metode case based reasoning. Penelitian ini bertujuan untuk membangun sistem pakar dalam menangani penyakit jahe berdasarkan nilai kemiripan tertinggi dan sesuai dengan analisa pakar penanganan penyakit tanaman jahe. Penerapan sistem pakar ini menghasilkan hasil penanganan berdasarkan kemiripan berupa penyakit, nilai kemiripan (similarity). Menurut pakar jahe, ada 22 (dua puluh dua) gejala penyakit jahe diberi kode G1 s.d G22 dan 6 (enam) jenis penyakit diberi kode P1 s.d P6. Dari studi kasus diperoleh Similarity untuk P1=2,8/6,5 sebesar 0,4307 P2=1,8/6,5 sebesar 0,2769, $P 3=1 / 6,5$ sebesar $0,1538, P 4=1,4 / 6,5$ sebesar $0,2153, P 5=2 / 6,5$ sebesar $0,1846 P 6=1,1 / 6,5$ sebesar 0,1692 . Hasil kasus lama, nilai kemiripan tertinggi: penyakit layu bakteri [P1], tingkat kemiripan $43 \%$. Perhitungan nilai kemiripan berdasarkan kasus lama yaitu menjumlahkan semua gejala yang dipilih dan membagikan nilai total gejala penyakit secara keseluruhan, dihasilkan nilai gejala baru=0,15. Hasil kasus baru menghasilkan nilai kedekatan pada penyakit buncak akar, kode penyakit=P3 (Penyakit bercak daun) dan bernilai sebesar 0.2307 .
\end{abstract}

Keywords - Ginger Pests, Symptoms, Case Based Reasoning Methods, Similarity

\section{Latar Belakang}

Jahe merupakan tanaman berupa tumbuhan berbatang temu dan termasuk dalam komunitas rempah-rempah yang diperdagangkan di dunia. Tanaman jahe dapat terserang penyakit yang mengakibatkan tanaman tidak dapat tumbuh dengan subur bahkan mati. Berdasarkan data statistik BPS Indonesia, produksi jahe di Indonesia tahun 2010 sebesar $109.024 .465 \mathrm{~kg}$, tahun 2011 turun menjadi $94.743 .139 \mathrm{~kg}$, tahun 2012 turun lagi menjadi $56.288 .984 \mathrm{~kg}$, dan tahun 2013 meningkat hampir dua kali lipat menjadi $105.926 .569 \mathrm{~kg}$. Dilihat dari data statistik tersebut terjadi penurunan drastis produksi jahe Indonesia di tahun 2012 yang hanya sebesar 56.288.948 kg. Di Indonesia serangan hama pada tanaman jahe menyebabkan petani kehilangan hasil rimpang jahe sampai $90 \%$ apabila tidak cepat ditanggulangi [1]. Penanganan penyakit jahe sangat penting dan perlu seorang paka, kenyataannya sulit menemukan keberadaan pakar pada bidang tanaman jahe mengenai masalah penyakit tanaman jahe dan penanganannya serta minimnya informasi yang didapatkan. Pengetahuan-pengetahuan dan pengalaman dari ahli pakar mengenai penyakit tanaman jahe disimpan dalam program. Sistem pakar menawarkan hasil yang lebih khusus untuk dimanfaatkan, sistem pakar berfungsi konsisten seperti seorang pakar manusia. Sistem pakar (Turban, 2005) adalah sistem informasi berbasis komputer yang menggunakan pengetahuan pakar untuk mencapai performa keputusan yang tinggi dalam domain persoalan sempit [2]. Sistem pakar (expert system) adalah sistem yang berusaha mengadopsi pengetahuan manusia ke komputer, agar komputer dapat menyelesaikan masalah seperti yang biasa dilakukan oleh para ahli [3]. Dalam penelitian yang telah dilakukan oleh Francisca Octaviani S berjudul Implementasi Case Based Reasoning Untuk Sistem Diagnosis Penyakit Anjing menjelaskan bahwa aplikasi sistem pakar dengan metode $C B R$ dengan menganlisis kasus baru dengan kasus lama dan mencari nilai similarity (kemiripan) sehingga dilakukan empat tahap retrieve, reuse, revisi dan retain sehingga solusi ditemukan [4]. 
Dalam menyelesaikan sistem cerdas ini dapat digunakan beberapa metode, untuk perbandingan namun dalam penerapan sistem cerdas identifikasi penyakit jahe, menggunakan metode Case Based Reasoning dengan penalaran membandingkan kasus baru dengan kasus lama dan didapatkan similarity dari perbandingan bobot. [5].

\section{Metode}

\section{Case Based Reasoning}

Case Based Reasoning adalah metode untuk menyelesaikan masalah dengan mengingat kejadiankejadian yang sama / sejenis (similar) yang pernah terjadi di masa lalu kemudian menggunakan pengetahuan / informasi tersebut untuk menyelesaikan masalah yang baru, atau dengan kata lain menyelesaikan masalah dengan mengadaptasi solusi-solusi yang pernah digunakan di masa lalu [6]. Tahapan proses yang terjadi dalam case based reasoning dibutuhkan empat 4 tahap, yaitu [7], [8]:

1. Retrieve, tahap pencarian tingkat kemiripan kasus inputan gejala yang diberikan pasien dengan kasus yang ada pada knowledge base untuk mencari kasus yang memiliki persamaan (similaritas) tertinggi.

2. Reuse, tahap perhitungan nilai similaritas (kemiripan) setiap kasus tertinggi yang sebelumnya telah dilakukan pencocokan dari kasus baru ke dalam kasus yang lama, sehingga dari hasil perhitungan nilai persamaan similarity didapatkan usulan solusi. Nilai similarity setiap kasus diperoleh dari : (Jumlah nilai gejala similarity terpilih $\mathrm{x}$ bobot) / total nilai bobot gejala dalam data kasus lama).

3. Revise, tahapan solusi kasus, misal saran obat dari hasil diagnosa. Sistem akan menghasilkan solusi yang telah dikembangkan dan disimpan dalam sistem untuk dijadikan pengetahuan baru.

4. Retain, solusi yang sudah diperbaiki akan disimpan sebagai data rekam medis pasien. Jika pakar menyatakan kasus baru tersebut sebagai kasus valid maka kasus baru tersebut dapat di-update kedalam basis kasus.

Konsep Similarity adalah konsep dasar geometri di dalam matematika yang mengekspresikan kemiripan dua (2) obyek. Dua obyek dikatakan mirip apabila kedua obyek tersebut memiliki bentuk yang sama. Dengan kata lain, tidak terdapat perbedaan yang signifikan dari dua buah obyek secara geometri. Konsep Similarity ini digunakan untuk melakukan perhitungan kemiripan dua buah kasus. Sering kali, konsep similarity juga digunakan untuk mengukur kemiripan dua buah obyek dalam bentuk dua dimensi ataupun tiga dimensi.

Nilai suatu kemiripan berkisar antara $0-1.0$ berarti dua buah obyek sama persis. Sedangkan 1 berarti dua buah obyek berbeda sama sekali. Semakin mendekati nilai 0, dua buah obyek tersebut dapat dikatakan memiliki kemiripan.

Rumus penghitungan kedekatan antara kasus lama dengan kasus baru adalah sebagai berikut:

$$
\mathrm{S}_{1} \times \mathrm{W}_{1}+\mathrm{S}_{2} \times \mathrm{W}_{2}+\mathrm{S}_{\mathrm{n}} \times \mathrm{W}_{\mathrm{n}}
$$

Similarity $(T, S)$

$$
\mathrm{W}_{1}+\mathrm{W}_{2}+\ldots . .+\mathrm{Wn}
$$

Keterangan:

$\mathrm{T}$ : Kasus baru

$\mathrm{S}$ : Kasus yang ada dalam penyimpanan, similarity (nilai kemiripan) yaitu 1 (sama) dan 0 (beda)

$\mathrm{n}$ : Jumlah atribut dalam setiap kasus

$\mathrm{i}$ : Atribut individu antara 1 s.d. $\mathrm{n}$

W : Bobot yang diberikan pada atribut

$\mathrm{S}=$ similarity (nilai kemiripan) yaitu 1 (sama) dan 0 (beda)

$\mathrm{W}=$ weight (bobot yang diberikan)

Analisa Data

\begin{tabular}{|c|c|c|}
\hline Kode & Gejala & Bobot \\
\hline G01 & Daun menguning & 0.4 \\
\hline G02 & Daun menggulung & 0.2 \\
\hline G03 & Daun layu & 0.2 \\
\hline G04 & Daun kering & 0.2 \\
\hline G05 & Batang hitam membusuk & 0.3 \\
\hline G06 & Tunas membusuk dan mati rebah & 0.2 \\
\hline G07 & Terdapat cairan putih pada batang & 0.3 \\
\hline G08 & Adanya eksudat bakteri & 0.3 \\
\hline G09 & Akar membusuk dan berwarna hitam & 0.2 \\
\hline G10 & Tanaman kerdil & 0.3 \\
\hline G11 & Water seal & 0.2 \\
\hline G12 & Timbul bercak pada daun & 0.2 \\
\hline G13 & Jahe Kering & 0.2 \\
\hline G14 & $\begin{array}{l}\text { Rimpang Jahe busuk dan berwarna } \\
\text { coklat }\end{array}$ & 0.4 \\
\hline G15 & Akar dan Batang Kering & 0.5 \\
\hline G16 & $\begin{array}{l}\text { Akar dan Batang membusuk dan } \\
\text { keropos }\end{array}$ & 0.3 \\
\hline G17 & Akar luka & 0.3 \\
\hline G18 & Patogen tanah mudah masuk & 0.3 \\
\hline G19 & Jahe Keropos & 0.5 \\
\hline G20 & Jahe Keriput & 0.3 \\
\hline G21 & Kulit rimpang kusam & 0.4 \\
\hline G22 & Daun membusuk dan berwarna hitam & 0.3 \\
\hline
\end{tabular}

Tabel 1 Gejala Penyakit Tanaman Jahe

Tabel 2 Jenis Penyakit Jahe Dan Solusi

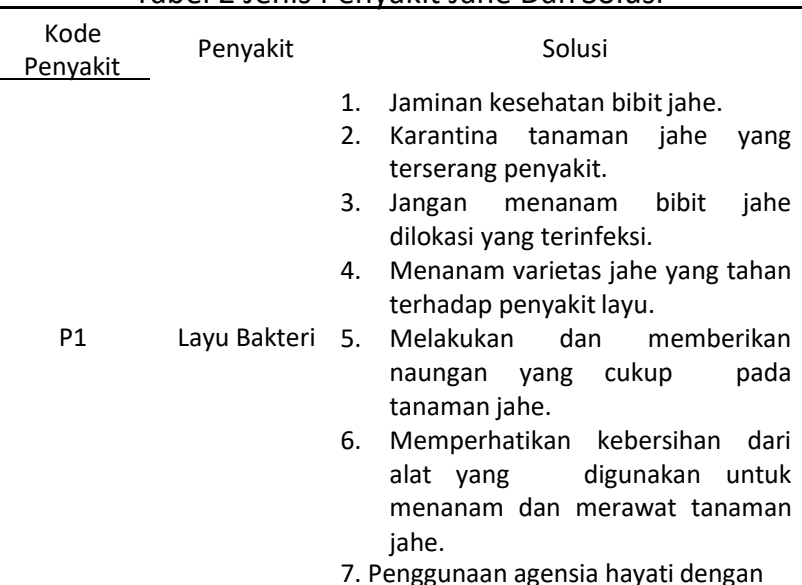




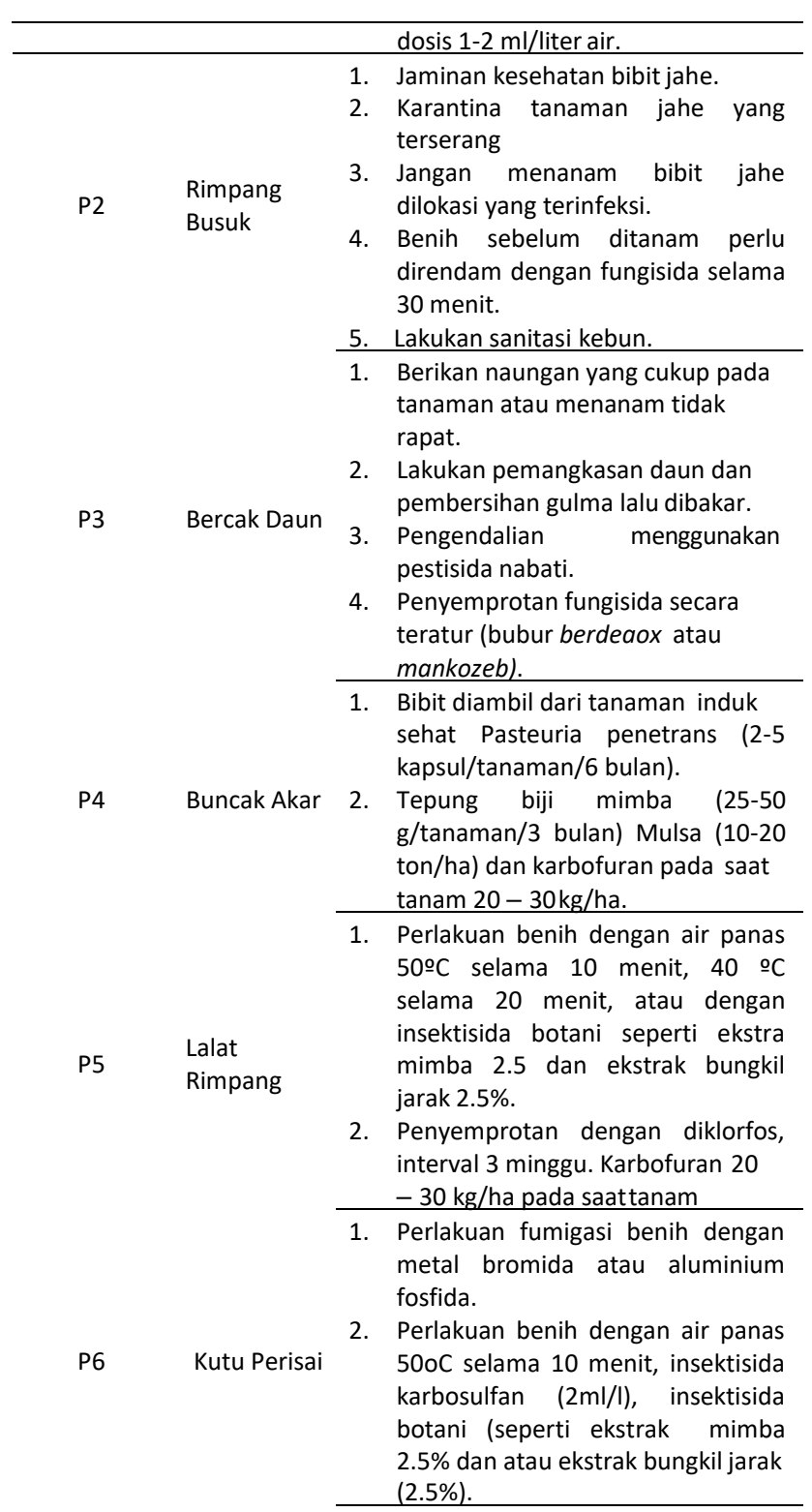

Tabel 3 Tabel Penyakit

\begin{tabular}{|c|c|c|c|c|c|c|}
\hline $\begin{array}{c}\text { KD } \\
\text { Gejala } \\
\end{array}$ & P1 & P2 & P3 & P4 & P5 & P6 \\
\hline G01 & $\checkmark$ & $\checkmark$ & $\checkmark$ & & & \\
\hline $\mathrm{G} 02$ & $\checkmark$ & & & & & \\
\hline $\mathrm{G} 03$ & $\checkmark$ & $\checkmark$ & $\checkmark$ & & & \\
\hline G04 & $\checkmark$ & & $\checkmark$ & & & \\
\hline G05 & $\checkmark$ & & & & & \\
\hline G06 & $\checkmark$ & & & & & \\
\hline G07 & $\checkmark$ & & & & & $\checkmark$ \\
\hline $\mathrm{G} 08$ & $\checkmark$ & & & & & \\
\hline G09 & $\checkmark$ & & & & & \\
\hline G10 & $\checkmark$ & $\checkmark$ & & & & \\
\hline G11 & $\checkmark$ & & & & & \\
\hline G12 & & & $\checkmark$ & & & \\
\hline G13 & & $\checkmark$ & & & & $\checkmark$ \\
\hline G14 & & $\checkmark$ & & & $\checkmark$ & \\
\hline G15 & & & & $\checkmark$ & & $\checkmark$ \\
\hline G16 & & & & $\checkmark$ & & \\
\hline G17 & & & & $\checkmark$ & & \\
\hline
\end{tabular}

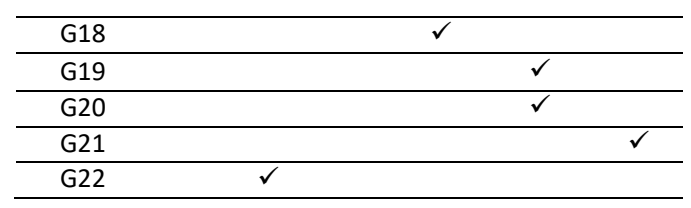

Representasi pengetahuan $C B R$ merupakan kumpulan kasus (case base) yang pernah terjadi sebelumnya. CBR menggunakan solusi dari kasus terdahulu yang mirip dengan kasus saat ini untuk menyelesaikan permasalahan

\section{Perancangan Sistem}

Use case merupakan fungsionalitas dari suatu sistem, sehingga pengguna sistem paham dan mengerti mengenai kegunaan sistem yang akan dibangun (Gambar 1).

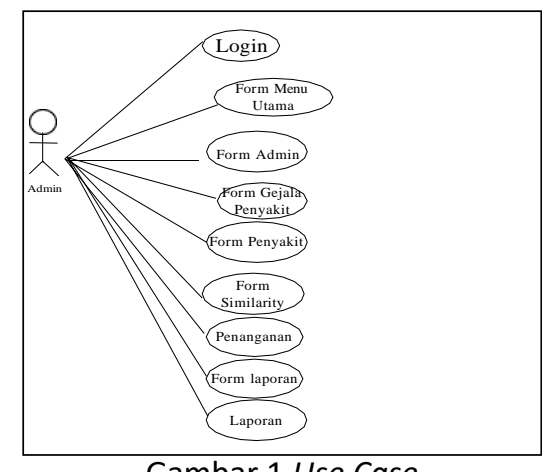

3. Hasil

Gambar 1 Use Case

\section{Studi Kasus}

Tanaman Jahe dengan kasus lama, diketahui:

1. Penyakit Layu Bakteri (P1)

Gejala :

[G1] Daun menguning

[G2] Daun menggulung

[G3] Daun Layu

[G4] Daun kering

[G5] Batang hitam membusuk

[G6] Tunas membusuk dan mati rebah

[G7] Terdapat cairan putih pada batang

[G8] Adanya eksudat bakteri

[G9] Akar membusuk dan berwarna hitam

[G10] Tanaman kerdil

Total nilai bobot $\mathrm{P} 1-\mathrm{P} 6=6.5$

$\mathrm{P} 1=[\mathrm{G} 1]+[\mathrm{G} 2]+[\mathrm{G} 3]+[\mathrm{G} 4]+[\mathrm{G} 5]+[\mathrm{G} 6]+[\mathrm{G} 7]+[\mathrm{G} 8]+$ $[\mathrm{G} 9]+[\mathrm{G} 10]=2,8$. Similarity $\mathrm{P} 1=2,8 / 6,5$ sebesar $=$ 0,4307

2. Penyakit Rimpang Busuk (P2)

Gejala:

[G1] Daun menguning

[G22] Daun membusuk dan berwarna hitam

[G13] Jahe kering dan layu

[G3] Daun layu dan tanaman mati

[G14] Rimpang busuk warna coklat

[G10] Tanaman kerdil

Program Studi Teknik Informatika 
$\mathrm{P} 2=[\mathrm{G} 1]+[\mathrm{G} 22]+[\mathrm{G} 13]+[\mathrm{G} 3]+[\mathrm{G} 14]+[\mathrm{G} 10]=1,8$

Similarity untuk P2 =1,8 / 6,5 sebesar 0,2769

3. Penyakit Bercak Daun(P3)

Gejala:

[G1] Daun menguning

[G3] Daun layu

[G4] Daun kering

[G12] Timbul bercak pada daun

$\mathrm{P} 3=[\mathrm{G} 1]+[\mathrm{G} 3]+[\mathrm{G} 4]+[\mathrm{G} 12]=1$.

Similarity untuk $P 3=1 / 6,5$ sebesar 0,1538

4. Rimpang Buncak Akar (P4)

Gejala:

[G14] Akar dan batang kering

[G16] Akar dan batang membusuk dan keropos

[G17] Akar luka

[G18] Patogen tanah muda masuk

$\mathrm{P} 4=[\mathrm{G} 14]+[\mathrm{G} 16]+[\mathrm{G} 17]+[\mathrm{G} 18]=1,4$

Similarity untuk P4 = 1,4 / 6,5 sebesar 0,2153

5. Penyakit Lalat Rimpang (P5)

Gejala:

[G19] Jahe keropos

[G14] Jahe membusuk

[G20] Jahe keriput

$\mathrm{P} 5=[\mathrm{G} 19]+[\mathrm{G} 14]+[\mathrm{G} 20]=1,2$

Similarity P5 = 1,2 / 6,5 sebesar 0,1846

6. Penyakit Kutu Perisai (P6)

Gejala:

[G21] Kulit rimpang kusam

[G13] Jahe kering

[G15] Akarkering

P6 $=[G 21]+[G 13]+[G 15]=1,1$

Similarity P6 = 1,1 / 6,5 sebesar 0,1692.

Hasil analisa metode Case based reasoning (CBR) pada penyakit tanaman jahe (Tabel 4)

Tabel 4 Hasil Perhitungan Similarity

\begin{tabular}{llll}
\hline $\mathrm{P}$ & $\begin{array}{c}\text { Total Nilai } \\
\text { Bobot } \mathrm{P}\end{array}$ & \multicolumn{1}{c}{ Similarity $\mathrm{P}$} & $\begin{array}{c}\text { Hasil Metode } \\
\text { CBR }\end{array}$ \\
\hline P1 & 2,8 & $2,8 / 6,5$ & 0,4307 \\
\hline P2 & 1,8 & $1,8 / 6,5$ & 0,2769 \\
\hline P3 & 1 & $1 / 6,5$ & 0,1538 \\
\hline P4 & 1,4 & $1,4 / 6,5$ & 0,2153 \\
\hline P5 & 1,2 & $1,2 / 6,5$ & 0,1846 \\
\hline P6 & 1,1 & $1,1 / 6,5$ & 0,1692 \\
\hline
\end{tabular}

Penyakit Tanaman jahe yang mempunyai nilai kemiripan tertinggi untuk kasus lama adalah penyakit layu bakteri [P1] dengan dengan tingkat kemiripan $43 \%$.

Studi Kasus Baru pada gejala penyakit tanaman jahe: Gejala [G01]: Daun menguning, [G02]: Daun menggulung [G03]: Daun layu, [G09]: Akar membusuk dan berwarna hitam, [G10]:Tanaman Kerdil, [G11]:Water seal.

Bobot : $\mathrm{G} 01$ (0.4), G02 (0.2), G03 (0.3), G09 (0.2), G10 (0.2), G11 (0.2).

Program Studi Teknik Informatika

Universitas Prima Indonesia (UNPRI) Medan
Perhitungan nilai kemiripan berdasarkan kasus lama adalah dengan menjumlahkan semua gejala yang dipilih dan membagikan nilai total gejala penyakit secara keseluruhan, maka dihasilkan sebesar nilai gejala baru adalah sebesar 0,15. Maka hasil yang didapatkan untuk nilai kemiripan dari sebelumnya adalah lebih menghasilkan nilai kedekatan pada penyakit buncak akar. Kode penyakit yang dibuat adalah P3 (Penyakit bercak daun) dan bernilai sebesar 0.2307 .

\section{Implementasi Sistem}

Tampilan form Sistem Pakar penanganan masalah penyakit jahe (Gambar 2), setiap user (petani) menginput biodata.

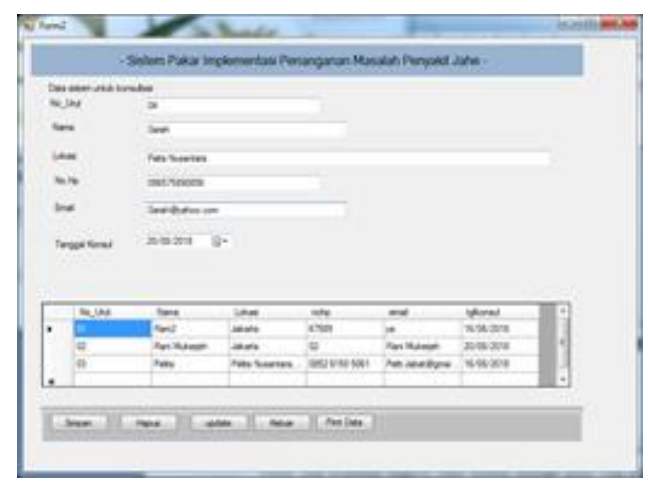

Gambar 2 Form Input Data User

Form Penanganan digunakan untuk memilih gejala untuk melakukan proses konsultasi dan mendapatkan hasil. User dapat memilih beberapa gejala yang muncul pada penyakit jahe. Setelah memilih gejala maka dapat menekan tombol periksa untuk mendapatkan hasil diagnosa dan nilai similarity dari nilai yang tertinggi kemiripannya akan ditampilkan penanganannya.

\section{Kesimpulan}

1. Hasil pada kasus lama Penyakit tanaman jahe nilai metode Case based reasoning (CBR) yang paling tinggi $\mathrm{P} 1=0.4307$, penyakit layu bakteri [P1] dengan dengan tingkat kemiripan $43 \%$.

2. Hasil kasus baru tanaman jahe total gejala penyakit secara keseluruhan $=0,15$. Hasil nilai kemiripan dari sebelumnya adalah lebih menghasilkan nilai kedekatan pada penyakit buncak akar, kode penyakit = P3 (Penyakit bercak daun) dan bernilai sebesar 0.2307.

3. Sistem pakar dalam penanganan masalah penyakit jahe dapat menampilkan hasil penanganan berupa nama penyakit, nilai similarity dan solusi berdasarkan penyakit yang muncul atau memiliki nilai kemiripan tertinggi. 


\section{Ucapan Terima Kasih}

Ucapan terima kasih pada seluruh Civitas Penusa Medan dan Independent Researcher ASST.

\section{Referensi}

[1] Otih, "Peluang Pengembangan Bahan Tanaman Jahe Unggul Untuk Penanggulangan Penyakit Layu Bakteri", Balai Penelitian Tanaman Obat dan Aromatik, hal : 77-100.

[2] Hartatik, I Ketut Putra, Sistem Pakar untuk Mendeteksi Hama dan Penyakit Tanaman Jahe Menggunakan Teorema Bayes. Teknik Informatika STMIK AMIKOM Yogyakarta, 16 (2), 27-31. 2015.

[3] SINAGA, Anita Sindar RM. bayes Diagnosa Penyakit Ikan Hias Air Tawar Dengan Teorema Bayes. SinkrOn, [S.I.], v. 3, n. 1, p. 43-50, Sep. 2018.

[4] Rabiah Adawiyah, "Case Based Reasoning Untuk Diagnosis Penyakit Demam Berdarah", Jurnal INTENSIF, Vol.1, No.1, hal 63-73, Februari 2017.

[5] Edi Faizal, "Case Based Reasoning Diagnosis Penyakit Cardiovascular Dengan Metode Simple Matching Coefficient Similarity", Jurnal Teknologi Informasi dan Ilmu Komputer (JTIIK)Vol.1, No. 2, hlm. 83-90, Oktober 2014.

[6] Arno Reza Pahlawan, Setyawan Wibisono, “Implementasi Case Based Reasoning Untuk Sistem Diagnosis Hama Dan Penyakit Tanaman Cabe Merah Menggunakan Algoritma Similaritas Neyman", Prosiding SINTAK 2017, hal: 155-162, 2017.

[7] Diki Andita Kusuma, Chairani, "Rancang Bangun Sistem Pakar Pendiagnosa Penyakit Paru-Paru Menggunakan Metode Case Based Reasoning", Jurnal Infotel Vol. 6 No. 2 November 2014.

[8] Halim Budi Santoso, "Case based reasoning dan Similarity untuk Memprediksi Kondisi Keuangan Perusahaan", Jurnal Teknik Informatika dan Sistem Informasi, Volume 2 Nomor 2, hal: 209-220, Agustus 2016. 